\title{
The roles of bromide and precursor structures on DBP formation and species distribution
}

\author{
G.S. Wang* and P.L. Huang** \\ *Department of Public Health, National Taiwan University, 1 Jen-Ai Road, Sec. 1, Taipei, Chinese, \\ Taiwan (E-mail: gswang@ha.mc.ntu.edu.tw) \\ **Institute of Environmental Health, National Taiwan University, 1 Jen-Ai Road, Sec. 1, Taipei, Chinese, \\ Taiwan (E-mail: r92844003@ntu.edu.tw)
}

\begin{abstract}
This study investigates the role of bromide and the structure of precursors in DBPs formation. Resorcinol (1,3-dihydroxylbenzene) and 2,4-pentadiol were used to represent the aromatic and aliphatic precursors. Laboratory prepared hydrophilic organic acids was used to simulate the mixtures of the aqueous natural organic matter. The results showed that about $60 \%$ of the bromide was transformed into $\mathrm{HOBr}$ and $\mathrm{OBr}^{-}$by chlorine when the chlorine dosages was high $(5-20 \mathrm{mg} / \mathrm{L}$ of free chlorine). However, only $20 \%$ of bromide was transformed into $\mathrm{HOBr}$ and $\mathrm{OBr}^{-}$at low chlorine dosage $(1 \mathrm{mg} / \mathrm{L})$. Trihalomethane formation potential (THMFP) measurements showed that higher THMs formation was obtained at higher $\mathrm{pH}$ for 2,4pentadiol, mainly due to the presence of the bromo-THMs. For resorcinol, however, no bromo-THMs are formed at either $\mathrm{pH} 7$ or 9. For THMFP from hydrophilic organic acids, no apparent $\mathrm{pH}$ effect was observed. It is concluded that the higher THM formation at higher $\mathrm{pH}$ was mainly due to the formation of bromo-THMs from the aliphatic precursors. Similar trends are obtained in THMFP measurements for haloacetic acids formation potential (HAAFP).
\end{abstract}

Keywords 2,4-pentadiol; bromide; disinfection by-products; haloacetic acids; resorcinol; trihalomethane

\section{Introduction}

Due to the presence of toxic disinfection byproducts (DBPs) which result from the chlorination procedures in water treatment processes, the nature of dissolved natural organic matter (NOM) in surface water supplies has received public attention in recent years. In general, the DBP formation in water treatment processes can be described as (Singer, 2000):

$\mathrm{Cl}_{2}+\mathrm{Br}^{-}+\mathrm{NOM} \rightarrow$ various DBPs

In the chlorination unit, hypobromous acid $(\mathrm{HOBr})$ and hypobromite are formed when bromide $\left(\mathrm{Br}^{-}\right)$is present in the water (Heller-Grossman et al., 1993; Nokes et al., 1999). Since $\mathrm{HOBr}$ is a stronger oxidant than $\mathrm{HOCl}$, it will compete with $\mathrm{HOCl}$ in DBP formation and resulted in the shift of the DBPs speciations from chloro-DBPs to bromo-DBPs (Liang and Singer, 2003; Richardson et al., 2003). The distribution of chloro-DBPs and bromo-DBPs depends on the $\mathrm{Cl}_{2} / \mathrm{Br}^{-}$ratio (Chang et al., 2001). At a given $\mathrm{Br}^{-}$concentration, increase the chlorine dosage increases the chloro-DBPs formation (such as chloroform).

The nature of NOM will also affect the final DBP species formed after chlorination (Li et al., 2000; Westerhoff et al., 2004). Composition of NOM in natural water includes predominantly humic acid and fulvic acid, as well as trace amounts of amino acids, fatty acids, and other products of microbial degradation. The removal of NOM from raw water is largely achieved by chemical coagulation and flocculation. It is generally believed that 
humic fraction of NOM is more amenably removed by coagulation, and only nonhumic fraction of NOM remains in treated water. The nonhumic fraction of NOM was considered to exist in clear water, without causing water quality problems. However, it has been reported that a significant amount of DBPs could result from nonhumic fraction of NOM. Although the well-established coagulation/flocculation treatment can considerably reduce organic residuals in drinking water, the treated water may require further purification to minimize the formation of DBPs (Xie, 2003).

The objective of this study is to investigate the role of bromide and the structure of precursors in the DBPs formation. Specific parameters considered include the equilibrium between $\mathrm{HOCl}$ and $\mathrm{HOBr}$ at various concentrations of $\mathrm{Cl}_{2}$ and $\mathrm{Br}^{-}$, the DBPs formation with different precursors at different experimental conditions, and DBP species distributions.

\section{Methods}

Humic acid from Aldrich was used in this study to prepare the stock solution, which contained $400 \mathrm{mg} / \mathrm{L}$ of non-purgeable dissolved organic carbon (NPDOC). Stock solution of humic acid was prepared by dissolving the humic acid extract in water at high $\mathrm{pH}$ $(>10)$ and the insoluble ash content was then filtered out by a $0.45 \mu \mathrm{m}$ filter paper. The stock solution of hydrophilic organic acids ( $\sim 40 \mathrm{mg} / \mathrm{L}$ of NPDOC) was then prepared by lowering the $\mathrm{pH}$ of humic acid stock solution to a value less than 1 , and the insoluble humic portion was filtered out by a $0.45 \mu \mathrm{m}$ filter paper. Before each experiment, the aqueous solution was prepared by diluting the hydrophilic organic acid stock solution to the desired concentration. The $\mathrm{pH}$ of the solution was adjusted to a suitable value with $0.1 \mathrm{~N}$ sulfuric acid or sodium hydroxide. For precursor study, 2,4-pentadiol and resorcinol (1,3-dihydroxylbenzene) were used to represent the aliphatic and aromatic precursors. Suitable amounts of 2,4-pentadiol or resorcinol were added into the laboratory prepared organic free water to the desired concentrations (as NPDOC).

The DBP formation potential (DBPFP) measurement follows the procedures for trihalomethane (THMFP) as described in section 5710B of Standard Methods (1998). Four THMs were quantified by a GC/MS (Hewlett Packard 6890GC/5973MSD) using a fused silica capillary column. The nine haloacetic acids (HAAs) were also determined with USEPA Standard Method 552.2 by a GC/MS using a DB5 capillary column. The NPDOC concentration was measured with a Total Organic Carbon analyzer (Shimadzu TOC 5000A). An ion chromatography (Dionex DX-120) equipped with Dionex AS4A-SC anion exchange column was used to measure the chloride and bromide concentrations.

\section{Results and discussion}

Equilibrium between $\mathrm{HOCl}$ and $\mathrm{HOBr}$ under various conditions

Bromide does not react with NOM directly. However, bromide will be oxidized by chlorine to form $\mathrm{HOBr}$ or $\mathrm{OBr}^{-}$, which will react with $\mathrm{NOM}$ to form bromo-DBPs (Cooper et al., 1985; Cowman and Singer, 1996). In order to elucidate the degree of transformation from $\mathrm{Br}^{-}$to $\mathrm{HOBr}$ and $\mathrm{OBr}^{-}, 0.5,1.0$ and $2.0 \mathrm{mg} / \mathrm{L}$ of $\mathrm{Br}^{-}$are spiked in laboratory prepared pure water (Milli-Q), and chlorine are then added into the $\mathrm{Br}^{-}$solutions at 1, 5, 10 and $20 \mathrm{mg} / \mathrm{L}$ as free chlorine. The residual $\mathrm{Br}^{-}$concentrations are then measured, and the concentrations of $\left[\mathrm{HOBr}+\mathrm{OBr}^{-}\right]$are calculated based on the mass balance of $\mathrm{Br}^{-}$in the solutions prepared with only $\mathrm{Br}^{-}$and $\mathrm{Cl}_{2}$ : 
therefore;

$\left[\mathrm{HOBr}+\mathrm{OBr}^{-}\right]=\left[\mathrm{Br}^{-}\right]_{\text {spiked }}-\left[\mathrm{Br}^{-}\right]_{\text {residual }}$

Figure 1 gives the concentration of $\left[\mathrm{HOBr}+\mathrm{OBr}^{-}\right]$at various $\mathrm{Br}^{-}, \mathrm{Cl}_{2}$ and $\mathrm{pH}$ conditions. As shown in Figure 1, although $\mathrm{pH}$ affects the distribution of $\mathrm{HOBr}$ and $\mathrm{OBr}^{-}, \mathrm{pH}$ causes no apparent change on the overall concentration of $\mathrm{HOBr}$ and $\mathrm{OBr}^{-}$ $\left(\left[\mathrm{HOBr}+\mathrm{OBr}^{-}\right]\right)$. As expected, the increase of bromide concentration in water results in higher concentration of $\mathrm{HOBr}$ and $\mathrm{OBr}^{-}$after reaction with chlorine. At higher chlorine dosages $(>5 \mathrm{mg} / \mathrm{L}$ of free chlorine), about $60 \%$ of the bromide will be transformed into $\mathrm{HOBr}$ and $\mathrm{OBr}^{-}$by chlorine. At low chlorine dosage $(1 \mathrm{mg} / \mathrm{L})$, only $20 \%$ of bromide will be transformed into $\mathrm{HOBr}$ and $\mathrm{OBr}^{-}$. Since $\mathrm{pKa}$ of $\mathrm{HOBr}$ is close to $8.7, \mathrm{HOBr}$ is considered to be the major oxidant than $\mathrm{Br}^{-}$at neutral $\mathrm{pH}(\sim 7)$. Figure 1 also shows that at lower concentrations of bromide or chlorine, the increases of $\mathrm{pH}$ decrease the $\mathrm{HOBr}$ and $\mathrm{OBr}^{-}$formation after chlorination. This trend is more apparent when both the concentrations of bromide or chlorine are low. The results in Figure 1 demonstrated that the ratio of the molar concentration of chlorine to bromide in the water is an important indicator to predict the speciation distribution of the disinfection byproducts. However, at

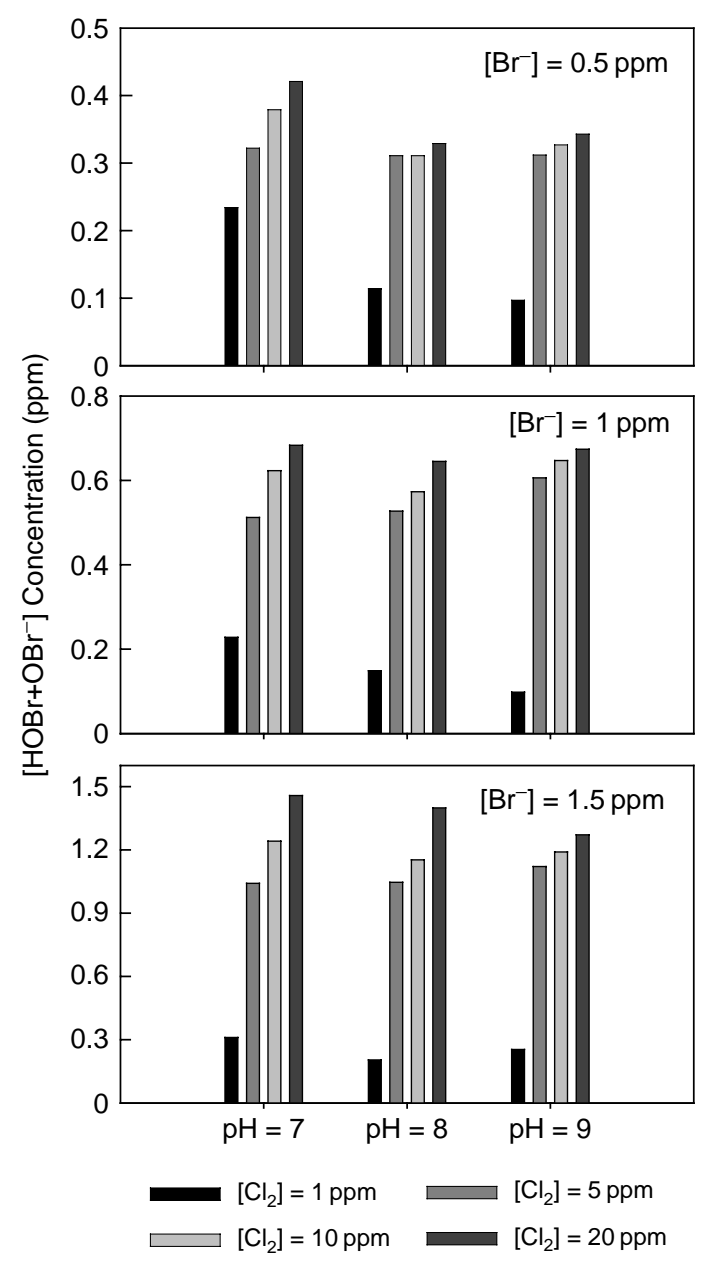

Figure 1 Concentration of $\mathrm{HOBr}$ and $\mathrm{OBr}^{-}$in laboratory prepared organic free water at various $\mathrm{pH}$ and 
lower applied chlorine dosages $(\sim 1 \mathrm{mg} / \mathrm{L})$ and low bromide concentrations $(\sim 0.5 \mathrm{mg} / \mathrm{L})$, $\mathrm{pH}$ may play a more important role than bromide since the transformation of bromide to $\mathrm{HOBr}$ and $\mathrm{OBr}^{-}$is low, and chlorine applied will dominate the formation of the disinfection byproducts at high $\mathrm{pH}$.

DBPs formation potential with model compounds under various conditions

It has been reported that neutral $\mathrm{pH}$ favors chloro-THM formation whereas the basic environment favors bromo-THM formation (Dore et al., 1982; Singer, 2000). It has also been reported that THM formation increases with increasing $\mathrm{pH}$, which is opposite to the trends of HAA formation. Therefore, the slightly acidic $\mathrm{pH}$ after coagulation promotes HAA formation, and the slightly basic $\mathrm{pH}(7.0-8.0)$ in finished water favors THM formation in the distribution systems. Due to the complicated structure of the NOM, 2,4-pentadiol and resorcinol were used as the model compounds to represent for the aliphatic and aromatic NOM in the water (Boyce and Hornig, 1983). For comparison, hydrophilic organic acids prepared from Aldrich humic acids was used to simulate the mixtures of the aqueous NOM.

Figures 2 and 3 give the THMFP and HAAFP of 2,4-pentadiol, resorcinol and hydrophilic organic acids at different $\mathrm{pH}, \mathrm{Br}^{-}$concentrations, and chlorine dosages. Both

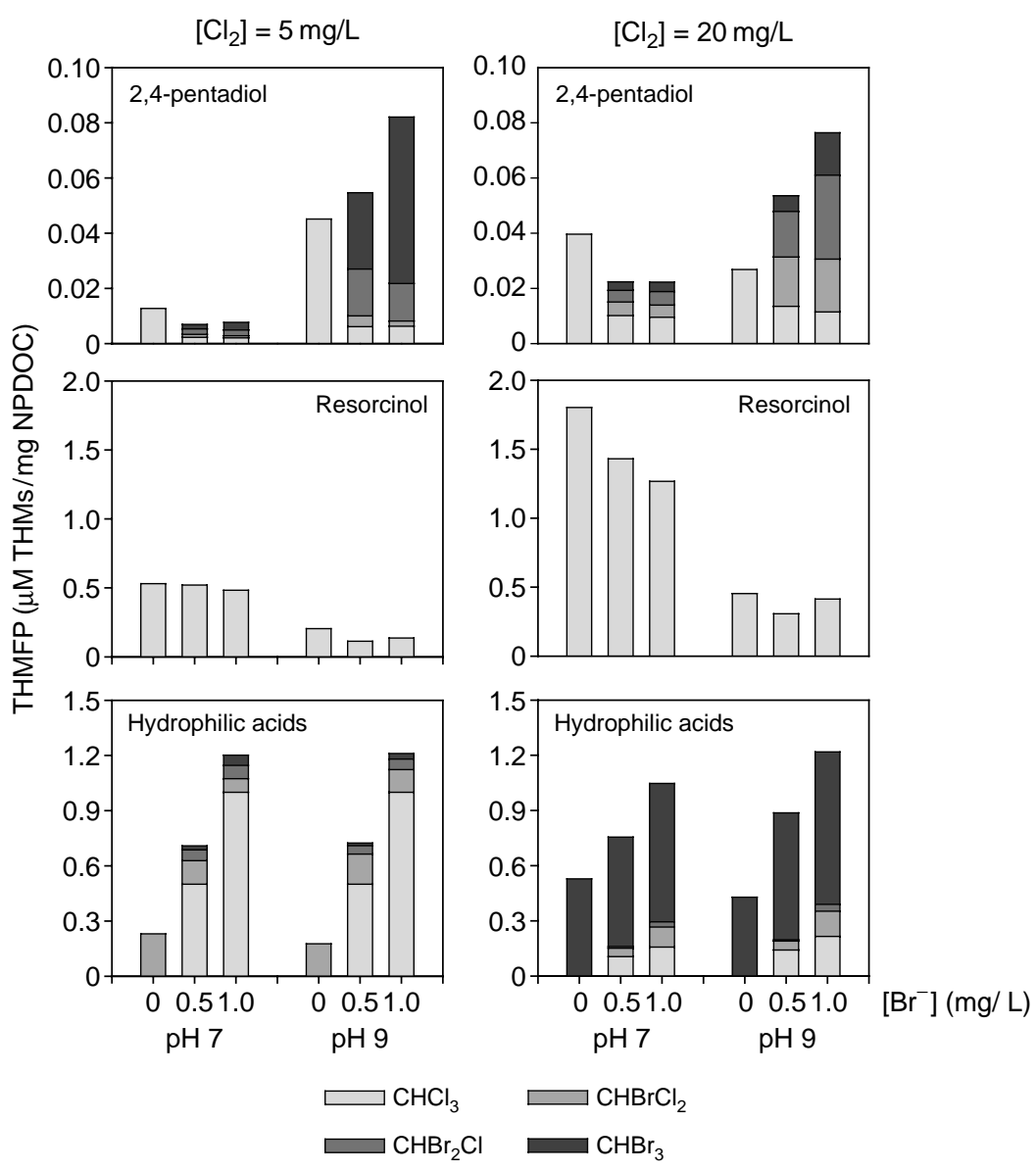

Figure 2 THMFP of 2,4-pentadial, resorcinol and hydrophilic organic acids at various $\mathrm{pH}^{\mathrm{N}}$ and $\mathrm{Br}^{-}$ 

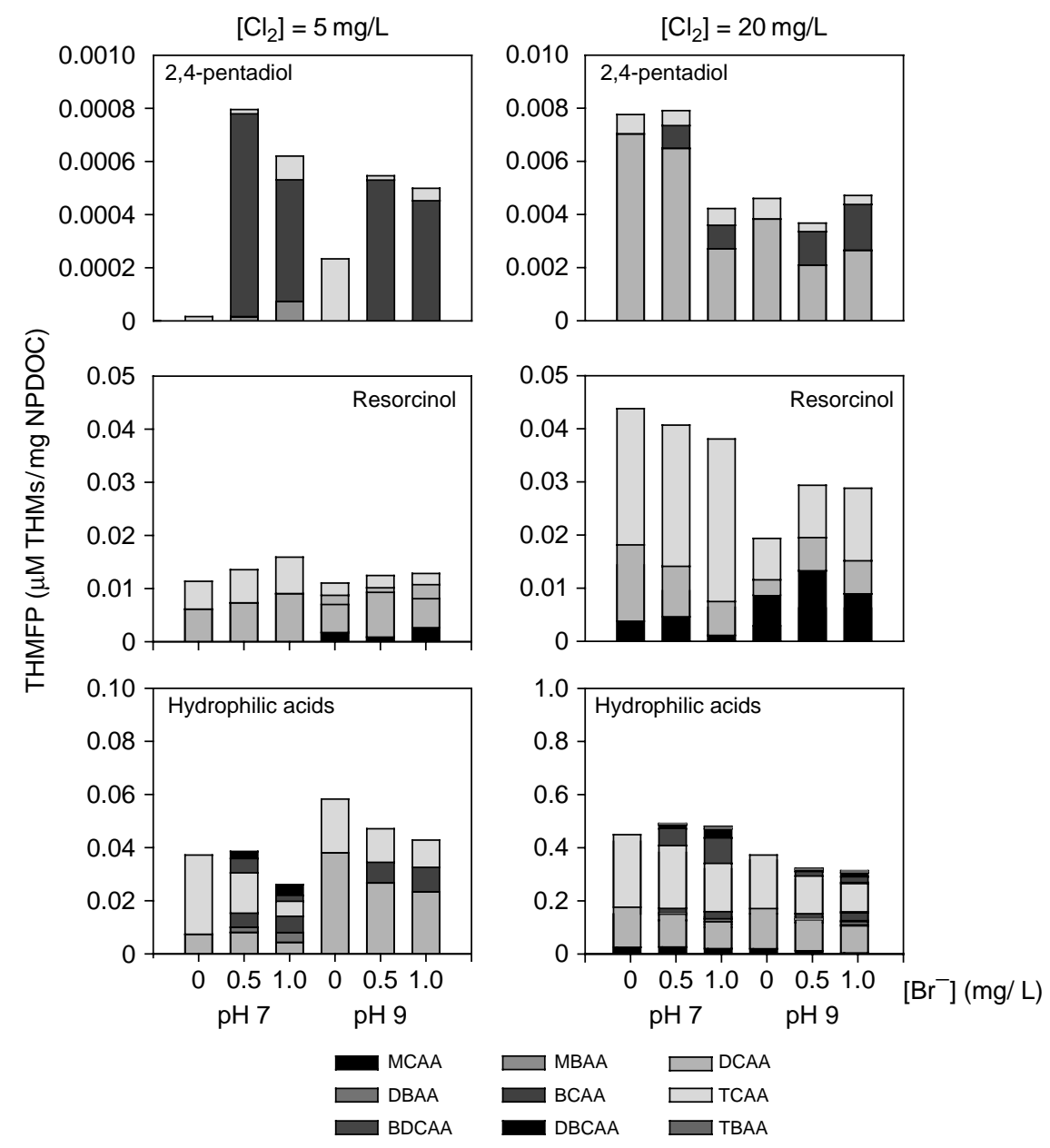

Figure 3 HAAFP of 2,4-pentadial, resorcinol and hydrophilic organic acids at various $\mathrm{pH}$ and $\mathrm{Br}^{-}$ concentrations. Data has been normalized to NPDOC concentrations

THMFP and HAAFP were given in molar concentrations and have been normalized to the NPDOC concentrations.

THMFP of model compounds and hydrophilic organic acids. Figure 2 shows that $\mathrm{pH}$ has different effect on THMs formation for 2,4-pentadiol and resorcinol. For 2,4pentadiol, higher THM formation was obtained at higher $\mathrm{pH}$, mainly due to the presence of the bromo-THMs. This high bromo-THMs formation is more apparent when the concentration of $\mathrm{Br}^{-}$is high, and this phenomenon is more apparent at high $\mathrm{pH}$. For resorcinol, no bromo-THMs are formed at either $\mathrm{pH} 7$ or 9. However, higher THMFP (solely chloroform) are observed at $\mathrm{pH} 7$ than at $\mathrm{pH}$ 9. Increase the chlorine dosage for resorcinol also greatly increases its THMFP; however, as shown in Figure 2, the presence of bromide decreases the chloroform concentration for resorcinol, but no bromo-THMs were formed, probably due to the transformation of $\mathrm{HOCl}$ to $\mathrm{HOBr}$. This result is different from those data observed for 2,4-pentadiol and hydrophilic organic acids, where higher chlorine dosage leads to higher THMFP. For precursors with functional groups of aliphatic structures, presence of bromide increases the bromo-THM formation after chlorination, and hence increases the overall concentrations of THMFP. THMFP with 
2,4-pentadiol and resorcinol indicate that $\mathrm{pH} 7$ favors chloroform formation with aromatic precursors like resorcinol; however, higher THMFP will be obtained at $\mathrm{pH} 9$ when aliphatic precursors like 2,4-pentadiol are present. Basic environment ( $\mathrm{pH}$ 9) also favors formation of bromo-THMs from aliphatic precursors. However, no apparent $\mathrm{pH}$ effect was observed when THMFP was measured with hydrophilic organic acids. For hydrophilic acids, higher chlorine dosage greatly increases the THMFP, at either $\mathrm{pH} 7$ or $\mathrm{pH}$ 9; and most of the increased THMFP comes from bromo-THM species. Since the hydrophilic organic acids was prepared from humic acids, the heterogeneous composition (contains both aromatic and aliphatic precursors) compromised the impact of different precursors. Based on the above discussions, it is concluded that the higher THM formation at higher $\mathrm{pH}$ was mainly due to the formation of bromo-THMs from the aliphatic precursors.

HAAFP of model compounds and hydrophilic organic acids. For various HAA species, similar trends are obtained as in THMFP measurements. As shown in Figure 3, the resorcinol only gives chloro-HAAs, where as 2,4-pentadiol gives both chloro- and bromo-HAAs. For resorcinol, increasing the chlorine dosage also greatly increases its HAAFP, and the HAA species shifts from monochlorine to dichlorine and trichlorine HAAs. Similar to those obtained in THMFP experiments, the presence of bromide decreases the chloro-HAAs formation from resorcinol, but it is not so apparent as those observed in THMs. Figure 3 also shows that $\mathrm{pH}$ has no apparent effect on HAA formation for 2,4-pentadiol and resorcinol when the chlorine dosage was $5 \mathrm{mg} / \mathrm{L}$. However, higher HAA formation was obtained at $\mathrm{pH} 7$ when the chlorine dosage is high $(20 \mathrm{mg} / \mathrm{L})$. Increasing the chlorine dosage will increase the chlorine numbers of HAA, and increasing the $\mathrm{Br}^{-}$concentration shifts the HAAs from chloro-HAAs to bromoHAAs. This observation is more apparent when hydrophilic organic acids are used for the HAAFP measurements, at either $\mathrm{pH} 7$ or $\mathrm{pH}$ 9. When the chlorine dosage was increased to $20 \mathrm{mg} / \mathrm{L}$, the HAAs formed is about ten times higher than those obtained at $5 \mathrm{mg} / \mathrm{L}$ of chlorine. However, some differences are observed for trihaloacetic acids (THAA) formation from hydrophilic organic acids. The neutral $\mathrm{pH}(\mathrm{pH} 7)$ favors the formation of bromo-THAA, but no bromo-THAA was obtained at $\mathrm{pH} 9$.

\section{Conclusion}

Although $\mathrm{pH}$ affects the distribution of $\mathrm{HOBr}$ and $\mathrm{OBr}^{-}, \mathrm{pH}$ causes no apparent change on the overall concentration of $\mathrm{HOBr}$ and $\mathrm{OBr}^{-}\left(\left[\mathrm{HOBr}+\mathrm{OBr}^{-}\right]\right)$. The increase of bromide concentration in water results in higher concentration of $\mathrm{HOBr}$ and $\mathrm{OBr}^{-}$. At higher chlorine dosages ( $>5 \mathrm{mg} / \mathrm{L}$ of free chlorine), about $60 \%$ of the bromide will be transformed into $\mathrm{HOBr}$ and $\mathrm{OBr}^{-}$by chlorine. At low chlorine dosage $(1 \mathrm{mg} / \mathrm{L})$, however, only $20 \%$ of bromide will be transformed into $\mathrm{HOBr}$ and $\mathrm{OBr}^{-}$. THMFP measurements of model compounds showed that $\mathrm{pH}$ has different effect on THMs formation for 2,4-pentadiol and resorcinol. For 2,4-pentadiol, higher THM formation was obtained at higher $\mathrm{pH}$, mainly due to the presence of the bromo-THMs. This high bromoTHMs formation is more apparent at high concentration of $\mathrm{Br}^{-}$and high $\mathrm{pH}$. For resorcinol, no bromo-THMs are formed at either $\mathrm{pH} 7$ or 9, but higher THMFP (chloroform) are observed at $\mathrm{pH} 7$ than at $\mathrm{pH}$ 9. No apparent $\mathrm{pH}$ effect was observed when THMFP was measured with hydrophilic organic acids. Similar trends are observed in HAAFP measurements, the resorcinol only gives chloro-HAAs, where as 2,4-pentadiol gives both chloro- and bromo-HAAs. 


\section{Acknowledgements}

This study was supported by National Science Council, Taiwan, Republic of China, under Grant No. NSC 93-2211-E-002-037.

\section{References}

Boyce, S.D. and Hornig, J.F. (1983). Reaction pathways of trilahomethane formation from the halogenation of dihydroxyaromatic model compounds for humic acid. Environmental Science and Technology, 17(4), $202-211$.

Chang, E.E., Lin, Y.P. and Chiang, P.C. (2001). Effects of bromide on the formation of THMs and HAAs. Chemosphere, 43(8), 1029-1034.

Cooper, W.J., Zika, R.G. and Steinhauer, M.S. (1985). Bromide-oxidant interactions and THM formation: a literature review. Journal of the American Water Works Association, 77(4), 116-121.

Cowman, G.A. and Singer, P.C. (1996). Effect of bromide ion on haloacetic acid speciation resulting from chlorination and chloramination of aquatic humic substance. Environmental Science and Technology, 30(1), 16-24.

Dore, M., Merlet, N., Laat De, and Goichon, J. (1982). Reactivity of halogens with aqueous micropollutants: a mechanism for the formation of trihalomethanes. Journal of the American Water Works Association, 74(2), 103-107.

Heller-Grossman, L., Manka, J., Limoni-Relis, B. and Rebhun, M. (1993). Formation and distribution of haloacetic acids, THM and TOX in chlorination of bromide-rich lake water. Water Research, 27(8), $1323-1331$

Li, C.W., Benjamin, M.M. and Korshin, G.V. (2000). Use of UV spectroscopy to characterize the reaction between NOM and free chlorine. Environmental Science and Technology, 34(12), 2570-2575.

Liang, L. and Singer, P.C. (2003). Factors influencing the formation and relative distribution of haloacetic acids and trihalomethanes in drinking water. Environmental Science and Technology, 37, 2920-2928.

Nokes, C.J., Fenton, E. and Randall, C.J. (1999). Modelling the formation of brominated trihalomethanes in chlorinated drinking waters. Water Research, 33(17), 3557-3568.

Richardson, S.D., Thruston, A.D., Rav-Acha, C., Groisman, L., Popilevsky, I., Juraev, O., Glezer, V., McKague, A.B., Plewa, M.J. and Wagner, E.D. (2003). Tribromopyrrole, brominated acid, and other disinfection byproducts produced by disinfection of drinking water rich in bromide. Environmental Science and Technology, 37(17), 3782-3793.

Singer, P.C. (2000). Formation and control of disinfection by-products in drinking water: an update. In Proceedings 6th International Workshop on Drinking Water Quality Management and Treatment Technology, Taipei, Taiwan.

Standard Methods for the Examination of Water and Wastewater (1998). 20th edn, American Public Health Association/American Water Works Association/Water Environment Federation, Washington, DC, USA.

Westerhoff, P., Chao, P. and Mash, H. (2004). Reactivity of natural organic matter with aqueous chlorine and bromide. Water Research, 38(6), 1502-1513.

Xie, Y.F. (2003). Disinfection Byproducts in Drinking Water: Formation, Analysis and Control, Lewis Publishers, New York, USA. 